\title{
Islam Nusantara Di Thailand; Studi Etnografi Ritual Ibadah Muslim di
} Thailand Selatan

\author{
Aliyul Himam ${ }^{1}$ \\ 1 UIN Sunan Ampel Surabaya \\ 1halo.himam@gmail.com
}

\begin{abstract}
Islam Nusantara or Islamic Nusantara is not just an Islamic concept in Indonesia only. Therefore, this paper focuses on how the manifestation of Islam Nusantara concept in Southern Thailand which refers to the manifestation of Islam Nusantara concept that has been applied in Indonesia. This research uses qualitative research with ethnographic approach. South Thai Muslims have a long relationship with Indonesia in genealogical, historical and cultural exchanges. So there is application of the concept of Islam Nusantara in Thailand with its various culture. The cultural form is grouped into language, practice, culture / custom, art, celebration, and worship.
\end{abstract}

Keywords: Islam Nusantara, Indonesia, Southern Thailand, Ritual, Worship, Culture

\section{Abstrak}

Islam Nusantara bukan hanya konsep Islam di Indonesia saja. Oleh karena itu tulisan ini memfokuskan pada bagaimana bentuk manifestasi konsep Islam Nusantara di Thailand Selatan yang mengacu pada bentuk manifestasi konsep Islam Nusantara yang telah diterapkan di Indonesia. Penelitian ini mengguanakan jenis penelitian kualitatif dengan pendekatan etnografis. Muslim Thailand Selatan mempunyai hubungan yang panjang dengan Indonesia secara genealogis, sejarah dan pertukaran budaya. Sehingga terdapat penerapan konsep Islam Nusantara di Thailand yang berbagai bentuk budaya. Adapun bentuk budaya tersebut dikelompokkan menjadi bahasa, amalan, budaya/adat, seni, perayaan, dan ibadah.

Kata Kunci: Islam Nusantara, Indonesia, Thailand Selatan, Ritual, Ibadah, Budaya

\section{Pendahuluan}

Islam merupakan agama rahmatan lil 'alamiin atau Islam sebagai pembawa rahmat bagi seluruh alam. Oleh karena inilah Islam bersifat universal, artinya, misi dan ajaran Islam tidak hanya ditujukan kepada satu bangsa atau negara saja, melainkan seluruh umat manusia, bahkan jagat raya. Namun demikian, pemaknaan universalitas Islam dalam kalangan umat muslim sendiri tidak seragam. Ada kelompok yang mendefinisikan bahwa ajaran Islam yang dibawa Nabi Muhammad yang notabenenya berbudaya Arab adalah final, sehingga harus diikuti sebagaimana adanya. Ada pula kelompok yang memaknai universalitas ajaran Islam sebagai yang tidak terbatas pada waktu dan tempat, sehingga bisa masuk ke budaya apapun. ${ }^{1}$

Pada mulanya, Islam di Makkah bertemu dengan budaya Makkah, lalu Islam yang menyebar kemudian bertemu dan berakulturasi dengan budaya setempat. Hingga dimana

${ }^{1}$ Khabibi Muhammd Luthfi, Islam Nusantara: Relasi Islam dan Budaya Lokal (Surakarta: Shahih, 2016), h. 2.

Jurnal Kopis: Kajian Penelitian dan Pemikiran Komunikasi Penyiaran Islam

Volume 2, issue 2, Februari 2020 
Islam sampai di kepulauan Nusantara ${ }^{2}$ (Indonesia) lalu berakulturasi dengan budaya Nusantara yang dulunya merupakan animisme dan dinamisme. Terlebih jika menelaah kembali metode dan strategi dakwah yang diterapkan oleh Wali Songo, yaitu Islam disebarkan dengan konfrontasi/kolonialisasi/penjajahan, melainkan penuh rahmat dan kasih sayang lebih mendahulukan cara dialog. Di samping itu masyarakat kerap dibiarkan menjalankan tradisi leluhurnya sambil sedikit demi sedikit ajaran tauhid diinjeksikan ke dalamnya. Memberantas kemungkaran pun tak dilakukan dengan cara-cara mungkar (alnabyu an al-munkar bi ghair almunkar). ${ }^{3}$ Sehingga, lambat-laun tanah Nusantara menjadi mayoritas memeluk agama Islam. Dari kisah romantisme masa kejayaan Islam inilah pada akhirnya tercipta wacana Islam Nusantara yang dipopulerkan oleh intelektual Nahdlatul Ulama' (NU) pada, maka Islam Nusantara tidak bisa lepas dengan NU.

Beberapa kebudayaan lokal Nusantara yang berakulturasi dengan Islam serta masih eksis dipraktikkan oleh muslim (terutama warga $\mathrm{Nabdliyin}^{4}$ ) adalah sesajen, ${ }^{5}$ memperingati 3 hari, 7, 14, 21, 100, dan 1000 harian setelah seseorang sanak keluarga meninggal, salat mayit beserta uang selawat, tablilan, ziarah kubur, yasinan, istighosah, maulid Nabi Muhammad, barjanzi (berjanjen), selametan, kenduri (genduri/kenduren), berkatan. Dalam ibadah juga terdapat amalan seperti puasa sunah, dua kali dalam khutbah Jumat, Idul Fitri dan Idul Adha, halal bi balal, tarawih 20/10 rakaat dan sholat witir menggunakan qunut pada setengah bulan terakhir. ${ }^{6}$ Dalam seni ada pagelaran wayang kulit, ketoprakan, jagongan dan tari-tarian, sholawat/syair dan sastra. Dalam pendidikan ada praktek pengajaran Pondok Pesantren, santri, bahasa pegon, kitab salaf/kuning dan lain sebagainya.

Masih banyak orang memahami Islam Nusantara hanya sebatas Islam di Indonesia, namun pada kenyataannya Islam Nusantara sudah ada di Thailand jauh sebelum Islam Nusantara dipopulerkan kembali oleh NU. Ditinjau dari segi teori dan strategi masuk hingga menyebarnya Islam di kepulauan Nusantara. ${ }^{7}$ Lalu di Thailand khususnya di Thailand bagian selatan tidak sedikit yang melakukan amaliah sepertihalnya kebudayaan lokal Indonesia yang disebut di atas. Di Thailand juga sering terdengar sholawatan atau lebih dikenal sebagai nasyid, berjanjen, ziarah kubur, yasinan, barjanzi (berjanjen), selametan, berkatan, maulid Nabi Muhammad. Dalam ibadah juga terdapat amalan seperti puasa sunah, dua kali dalam khutbah Jumat, Idul Fitri dan Idul Adha, halal bi halal, tarawih 20/10 rakaat dan sholat witir menggunakan qunut pada setengah bulan terakbir. Dalam bidang seni, jika di Indonesia ada pagelaran wayang kulit maka di Thailand juga ada yang disebut Nang Talung, jagongan juga dilakukan setelah ada kenduri atau kegiatan kemasyarakatan lain. Dan di Thailand juga ada praktek pengajaran Pondok Pesantren, lalu santri pondok bisa sampai 5000 santri dalam satu pondok, lalu di Thailand bahasa/tulisan pegon lebih dikenal sebagai bahasa jawi, juga kitab kuning/jawi mewarnai khasanah keilmuan muslim Thailand Selatan.

2 Nusantara merujuk pada kepulauan Melayu. Baca juga Deny Yudo Wahyudi "Kerajaan Majapahit: Dinamika Dalam Sejarah Nusantara" Sejarah dan Budaya, Tahun Ketujuh, Nomor 1, Juni 2013, juga Achmad Syafrizal, "Sejarah Islam Nusantara”, Islamuna, Volume 2 Nomor 2 Desember 2015 untuk pengayaan informasi.

${ }^{3}$ Mohamad Guntur Romli dkk, Islam Kita Islam Nusantara: Lima Nilai Dasar Islam Nusantara (Ciputat: Ciputat School, 2016), h. 143.

${ }^{4}$ Sebutan untuk muslim yang tergabung dalam Nahdlatul Ulama'

${ }^{5}$ Atur Kauningan "Tata Cara Bancakan Weton” 2012

${ }^{6}$ Lihat juga Sutejo Ibnu Pakar, Tuntutan Amaliah Ramadhan Warga Nahdhiyyin (Cirebon: Kamu NU, 2015) untuk memperkaya informasi.

7 Lihat juga Achmad Syafrizal, "Sejarah Islam Nusantara", Islamuna, Volume 2 Nomor 2 Desember 2015 untuk memperkaya informasi. 
Mohammad Guntur Romli dalam studinya memaparkan bahwa Islam Nusantara telah memperoleh basis keislaman yang kuat dari sisi syariat Islam, yakni pengakuan terhadap kelenturan syariat Islam, membaca sumber-sumber primer (Al-Quran dan Hadits) dari sisi maqashid al-syariah, melakukan optimalisasi terhadap sumber-sumber sekunder, serta optimalisasi terhadap kaidah-kaidah fikih sebagai penggalian hukum. Hal yang paling penting dalam konteks Islam Nusantara adalah peran adat yang disebut sebagai al-'urf atau al-adah atau juga syar'un man qablana (syariat sebelum kita/Islam) menunjukkan penerimaan terhadap kemuliaan adat-adat di Nusantara yang sering disebut sebagai kearifan-kearifan lokal. ${ }^{8}$ Quraish Shihab berpendapat bahwa akulturasi antara kearifan lokal dan agama kemudian oleh Islam dibagi menjadi tiga respon Islam terhadap budaya tersebut. Pertama, adakalanya Islam menolak budaya setempat. Kedua, Islam merevisi budaya yang telah ada. Ketiga, Islam hadir untuk menyetujui budaya yang telah ada tanpa menolak dan tanpa merevisinya. ${ }^{9}$

Khabibi Muhammad Luthfi dalam studinya menyebutkan jikalau konflik yang mengatasnamakan agama (Islam) yang tak kunjung usai di berbagai belahan dunia, terutama di Timur Tengah sebagai tempat kelahiran Islam, memunculkan keresahan di berbagai kalangan, termasuk umat Islam sediri. Dari sini muncul ide dan usaha dari intelektual muslim untuk mengekspor konsep Islam Nusantara ke seluruh dunia.

Berbicara tentang Islam Nusantara di kancah International. Dr. James B. Hoesterey dari Universitas Emory di Atlanta, Georgia, ia berpendapat terkait Islam Nusantara bahwa:

Sebagai seorang antropolog yang sudah lama melakukan penelitian di Indonesia, saya senang bahwa dunia luar dan wakil-wakil serta duta besar dari negara masing-masing dapat mendengarkan sedikit lebih dalam mengenai Islam di Indonesia yang mungkin tidak sama dengan; Islam di negara mereka, misalkan Arab Saudi. Kalau kita lihat ke depan, mungkin Indonesia bisa menjadi contoh bagi seluruh negara. ${ }^{10}$

Sedangkan menurut Dr. Chiara Formichi, pakar sejarah Islam di Indonesia, dari Universitas Cornell di Ithaca, New York, mengatakan:

Gagasan Islam Nusantara sangat erat dengan budaya dan sejarah Indonesia. Saya tidak tahu bisa diterapkan di negara lain atau tidak, tetapi yang jelas bisa menjadi contoh untuk mengerti mengapa seseorang memeluk Islam. Ada banyak cara untuk memahami Islam dan banyak cara untuk berinteraksi dengan non-Muslim. Muslim di sana juga punya banyak pengalaman berbeda. Jadi ada banyak pelajaran yang bisa dipetik. ${ }^{11}$

Lukman Saifuddin menerangkan wacana Islam Nusantara yang belakangan menjadi gagasan sebagian umat mengenai identitas Islam di Indonesia kini tengah menjadi perbincangan di dunia internasional. Dunia seakan tengah menempatkan Islam Indonesia sebagai model peradaban Islam modern. Dimana Istilah Islam Nusantara kini menjadi sebuah wacana yang mendunia, di banyak perguruan tinggi ternama di Eropa maupun di Amerika. Islam Nusantara menjadi diskursus dan akan menjadi sebuah term. ${ }^{12}$

Namun konsep Islam Nusantara ini masih belum matang, artinya penerapan, substansi dan esensinya masih tergolong abstrak, terlebih dalam dunia Internasional,

${ }^{8}$ Romli, dkk, Islam Kita, h. 92.

9 Queen Fannis Listia, BAB IV Islam Nusantara; Upaya Pribumisasi Islam Menurut NU (Surabaya: Digilib Uinsby, 2016), h. 1.

${ }^{10}$ Romli, dkk, Islam Kita, h. 22.

${ }^{11}$ Romli,

12 Romli, h. 20. 
dimana pembahasan konsep Islam Nusantara masih pada taraf diskusi dan belum ada penjelasan secara konkret bagaimana penerapan Islam Nusantara selain yang telah diterapkan di Indonesia.

Berdasarkan persoalan di atas, tulisan ini akan mengkaji bagaimana sajakah bentuk manifestasi konsep Islam Nusantara di Thailand Selatan yang mengacu pada bentuk manifestasi konsep Islam Nusantara yang telah diterapkan di Indonesia?

\section{Metode}

Penelitian ini mengguanakan jenis penelitian kualitatif dengan pendekatan etnografis. Alasan peneliti menggunakan jenis penelitian kualitatif etnografis dalam penelitian ini adalah untuk dapat mendeskripsikan hasil dari penelitian lebih mendalam dan holistik atau menyeluruh, sehingga hasil kajian peneliti bisa bersifat deskriptif-reflektif-eksplanatif. Moleong menyatakan bahwa metode kualitatif adalah prosedur penelitian yang menghasilkan data deskriptif berupa kata-kata atau lisan dari orang dan perilaku yang dapat diamati. Adapun teknik pengumpulan data dilakukan dengan cara: observasi, in-depth interview, dan studi pustaka. Data yang terkumpul selanjutnya dianalisis dengan menggunakan metode analisis interaktif Miles and Huberman dalam bukunya Qualitative Data Analysis: A Source Book of New Methods (1998) yang terdiri dari empat tahap, yaitu: pengumpulan data (data collecting), reduksi data (data reduction), penyajian data (data display) dan menarik kesimpulan (conclusion).Observasi dilakukan dengan cara pengamatan secara langsung terhadap kehidupan masyarakat Muslim di Thailand Selatan, meliputi provinsi Naratiwat, Yala, Patani, Songkhla, Satun, Trang, Nakhon Si Thammarat, Phattalung, dan provinsi Krabi dalam kurun waktu Mei - Oktober 2017. Adapun informan dari penelitian ini adalah: intelektual Muslim di Thailand khususnya Muslim yang berasal dari wilayah selatan, pejabat Konsulat Republik Indonesia Songkhla, masyarakat Indonesia yang sedang/pernah tinggal maupun studi di Thailand dan beberapa mahasiswa asal Thailand yang berkuliah di Indonesia. Adapun studi pustaka dilakukan dengan menelusuri dokumen terkait seperti majalah, surat kabar dan penelitian sebelumnya.

Penelitian ini memfokuskan pada bagaimana sajakah bentuk manifestasi konsep Islam Nusantara di Thailand Selatan yang mengacu pada bentuk manifestasi konsep Islam Nusantara yang telah diterapkan di Indonesia? Oleh karena itu tujuan dari penelitian ini adalah untuk mendeskripsikan dan memahami bagaimana saja bentuk manifestasi konsep Islam Nusantara di Thailand Selatan yang mengacu pada bentuk manifestasi konsep Islam Nusantara yang telah diterapkan di Indonesia. Adapun manfaat dari penelitian ini adalah, pertama, secara teoritis dapat memberikan sumbangan terhadap pengembangan Ilmu Komunikasi, khususnya kajian budaya (Cultural studies) secara mendalam. Kedua, secara praktis penelitian ini diharapkan dapat bermanfaat termasuk sebagai kajian yang diteliti terkait kajian budaya, serta dapat membantu masyarakat memahami bentuk manifestasi budaya keislaman di Indonesia dan Thailand dengan mengacu pada konsep Islam Nusantara.

\section{Hasil dan Pembahasan}

\section{Teori Islam Nusantara}

Membahas Nusantara tidak bisa merujuk pada satu model, corak, dan budaya, karena Nusantara merujuk pada keragaman yang ada di pulau-pulau Nusantara. Nusantara 
merupakan kumpulan dari pulau-pulau, yang tidak kurang dari 17.000 pulau. Nusantara adalah nama yang pernah diajukan oleh Ki Hajar Dewantara untuk menyebut wilayah Indonesia masa kini. Nusantara yang disebut Mpu Prapanca dalam Kakawin Nagarakretagama ${ }^{13}$ sebagai wilayah kekuasaan Kerajaan Majapahit meliputi Jawa, Sumatra, Semenanjung Malaya, Borneo, Sulawesi, kepulauan Nusa Tenggara, Maluku, Papua, dan sebagian kepulauan Filipina.

Maka, yang dimaksud Nusantara bukanlah Jawa, bahkan secara etimologi Nusantara berasal dari kata "nusa" yang berarti pulau, dan "antara" yang berarti lain/seberang, yakni pulau-pulau di seberang Jawa. Penyebutan Nusantara ini pula yang terkait dengan Kerajaan Majapahit untuk mengingatkan akan kebesaran masa lalu bangsa ini, yaitu bangsa yang besar dan pernah berjaya. " "Islam Nusantara" berbeda dengan term "Islam di Nusantara". Nusantara pada istilah yang pertama adalah sifat, dalam bahasa pesantren disebut "mudhafun ilaibi"-ia mensifati kata Islam, dalam istilah lain dapat diartikan menjadi "Islam Nusantarawi". Sedangkan istilah kedua: Islam di Nusantara hanya menunjukkan bahwa Nusantara hanya sebagai tempat saja, yang tidak memiliki hubungan, apalagi pengaruh terhadap Islam. Oleh karena itu "Islam Nusantara" bisa dipahami Islam dengan corak, warna, kekhasan, keunikan, karakter, budaya Nusantara. ${ }^{15}$

Corak keislaman yang beragam di Nusantara, telah melahirkan sejumlah teori masuknya Islam dari asalasal yang berbeda. Paling tidak ada 4 teori asal-usul masuknya Islam ke Nusantara seperti yang dirangkum oleh Agus Sunyoto dalam Atlas Wali Songo. Teori India (Gujarat, Malabar, Deccan, Coromandel, Bengal) hal ini berdasarkan asumsi persamaan madz̧ab Syafii, batu-batu nisan dan kemiripan tradisi dan arsitektur India dengan Nusantara. (JP Mosquette, C. Snouck Hurgronje, S.Q. Fatimy). Teori Arab (Mesir dan Hadramaut Yaman), berdasarkan persamaan dan pengaruh madzhab Syafii. (John Crawfurd, Naguib Al-attas). Teori Persia (Kasan, Abarkukh, Lorestan), berdasarkan kemiripan tradisi dengan muslim Syiah, seperti Peringatan Asyura (10 Mubarram), mengeja aksara Arab jabar (fathah), jer/zher (kasrah), fyes (dhammah), pemuliaan terhadap keluarga Nabi Muhammad Saw (Ablul Bayt) dan keturunannya. Penyebutan kata, rakyat (dari ra'iyyab), masyarakat (musyawarah), serikat (syarikah). (Husein Djajadiningrat, Hasjmi, Aboe Bakar Atjeh). Teori Cina yang berdasarkan asumsi pengaruh budaya Cina dalam sejumlah kebudaaan Islam Nusantara, dan sumber kronik dari Klenteng Sampokong di Semarang (De Graaf, Slamet Muljana). ${ }^{16}$

Menurut Agus Sunyoto kesuksesan islamisasi di tanah Jawa pada abad ke-15 H dengan kedatangan rombongan muslim dari Champa, Raden Rahmat (Sunan Ampel) sekitar tahun 1440 yang memiliki bibi yang diperistri Raja Majapahit. Selanjutnya Islamisasi dimulai melalui jaringan para juru dakwah (wali) secara terorganisir dan sistematis, mereka memanfaatkan jaringan kekeluargaan, kekuasaan, kepiawaian mereka merebut simpati masyarakat. Kekuatan gerakan ini terletak pada: (1) ajaran sufisme, (2) asimilasi dalam pendidikan, (3) dakwah lewat seni dan budaya dan (4) membentuk tatanan masyarakat muslim Nusantara. ${ }^{17}$

${ }^{13}$ Kitab sumber sejarah yang begitu dipercaya. Ditulis pada masa kerajaan Majapahit masih berdiri di bawah pemerintahan Sri Rajasanagara atau dikenal juga dengan nama Hayam Wuruk.

${ }^{14}$ Romli, dkk, Islam Kita, h. 24.

${ }^{15}$ Romli, 24.

${ }^{16}$ Romli, h. 37-38.

${ }^{17}$ Romli. h. 41 
Khabibi Muhammd Luthfi dalam studinya menyatakan bahwa Islam Nusantara memosisikan Islam sebagai sistem nilai, teologi, dan fiqib-ubudiyyah yang memengaruhi budaya Indonesia dengan karaktersitik tertentu. ${ }^{18}$ Fikih adalah satu bidang ilmu dalam syariat islam yang membahas permasalahan hukum yang mengatur aspek kehidupan pribadi, bermasyarakat maupun kehidupan manusia dengan sang Pencipta (Hablun minallah wa hablun minannas). Contoh hukum Wajib, Sunnat, Mubah, makruh dan Haram. Sedangkan ubudiyyah adalah sikap penghambaan manusia kepada sang Pencipta. Imam Ghozali pernah ditanya tentang ubuddiyah. Lalu Imam Ghozali menjawab:

Ubudiyyah itu kumpulan dari 3 hal, yaitu : Pertama, Menunaikan Perintah Syariat contoh : Menunaikan Salat. Kedua, rela dengan ketentuan dan takdir dan pembagian rezeki dari Allah SWT contoh: Cita-cita ingin menjadi Rektor Universitas Negeri Islam, tapi ternyata setelah berusaha ternyata menjadi petani. Ketiga, Meninggalkan kehendak nafsunya untuk mencari keridhaan Alloh SWT. Contoh: Nafsunya mengajak untuk bersenang--senang, lalu dikendalikan dengan zikir dan beramal saleh dengan keadaan mengharap ridho Allah SWT. ${ }^{19}$

Terkait dengan penyebaran Islam dan konsep Islam Nusantara yang sudah menjadi barang tentu akan terjadinya interaksi antar individu atau subyek kelompok, maka ada lima sikap yang dirumuskan oleh KH Ahmad Shiddiq ${ }^{20}$ untuk seorang muslim dalam menjalin hubungan antar manusia dan kehidupan sosial kemasyarakatan, yakni pandangan dan sikap yang: Tawassuth (moderat) Tawazun (berimbang) Tasamub (toleran) I'tidal (Tegak, Konsisten, Istiqamah) dan juga Amar Ma'ruf Nabi Mungkar (Mendorong perbuatan baik dan mencegah semua hal yang bisa menjerumuskan dan merendahkan nilai-nilai kehidupan). ${ }^{21}$ Selain itu, seorang muslim juga harus melakukan pengakuan terhadap pada tiga prinsip persaudaraan (al-ukhuwwah) dalam konteks keindonesiaan: Persaudaraan Keislaman (Ukhuwah Islamiyah), Persaudaraan Kebangsaan (Ukhuwah Wathaniyah), dan Persaudaraan Kemanusiaan (Ukhuwah Basyariyah).

Selain dalam hubungan sosial kemasyarakatan, dalam konteks Islam Nusantara yang paling penting adalah peran adat yang disebut sebagai al-'urf atau al-adah atau juga syar'un man qablana (syariat sebelum kita/Islam) menunjukkan penerimaan terhadap kemuliaan adat-adat di Nusantara yang sering disebut sebagai kearifan-kearifan lokal. ${ }^{22}$ Ketika kearifan lokal bertemu dengan Islam atau sebaliknya, maka akan terjadi sebuah akulturasi budaya di antara keduanya. Quraish Shihab berpendapat bahwa akulturasi antara kearifan lokal dan agama kemudian oleh Islam dibagi menjadi tiga respon Islam terhadap budaya tersebut. Pertama, adakalanya Islam menolak budaya setempat. Kedua, Islam merevisi budaya yang telah ada. Ketiga, Islam hadir untuk menyetujui budaya yang telah ada tanpa menolak dan tanpa merevisinya. ${ }^{23}$

Sebagaimana diketahui, bahwa Islam memiliki dua jenis ajaran. Pertama, adalah ajaran yang tetap dan tak berubah (al-tsawabit), sepertihalnya Aqidah. Di mana umat Islam di manapun harus meyakini tentang ke-esaan Allah SWT, kenabian Muhammad SAW, dan kewahyuan al-Qur'an al-Karim. Jadi tidak dibenarkan jika dengan alasan budaya, umat Islam

\footnotetext{
${ }^{18}$ Luthfi, Islam Nusantara: Relasi, h. 10.

${ }^{19}$ Waeancara dengan Kholilurrahman Chuldori.

${ }^{20}$ Rais Aam PBNU tahun 80-an.

${ }^{21}$ Romli, dkk, Islam Kita, ..., h. 92-93

${ }^{22}$ Romli, h. 92.

${ }^{23}$ Queen Fannis Listia, BAB IV Islam Nusantara, h. 1.
} 
Nusantara menolak ajaran tauhid monoteisme. Kedua, adalah ajaran yang tidak tetap dan dapat berubah (al-mutaghayyirat). Jenis ajaran kedua ini sebagian besar berada pada domain mu amalah, siyasah (politik), dan urf-ijtima $i$ (sosial-budaya). Pada bidang ini, Islam sesungguhnya lebih banyak bicara mengenai prinsip-prinsip etis-moral seperti tahqiq aladalah (mewujudkan keadilan), syura baynabum (musyawarah), ishlab dzati al-bayn (perdamaian) dan mu asyarah bi al-ma 'muf (pergaulan yang baik), lalu wujud al-taradhi (adanya kerelaan), izalah al-dharar (menghilangkan kemudaratan), 'adam al-ikrah (tak ada pemaksaan), dan ‘adam al-gharar (tak ada penipuan). Intinya, seluruh hal terkait relasi antar manusia, mulai dari lingkungan keluarga, masyarakat hingga negara harus didasarkan pada prinsip menarik maslahat (jalbu al-mashlahah) dan menolak mafsadat (dar'u almafsadah).

Selanjutnya, sejarah menunjukkan bahwa Islamisasi Nusantara berlangsung tanpa pertumpahan darah. Dalam menyebarkan Islam salah satu cara yang ditempuh para ulama adalah mendialektikkan Islam dengan kebudayaan. Dengan perkataan lain, hubungan antara Islam dan kebudayaan merupakan hubungan dialektik (alaqah jadaliyah) bukan hubungan dominatif (alaqah ikbda') artinya tidak ada penlenyapan antara satu dengan yang lainnya. Dengan menggunakan cara bil hikmah wal mau idah al-hasanah wal mujadalah bil husna, para ulama berhasil mengislamkan Nusantara. Dengan dakwah seperti ini, penduduk Nusantara-meminjam bahasa al-Qur'an-yadkhuluna fi dini Allah afwaja (mereka berbondong-bondong masuk Islam). Mungkin benar, Islam masuk ke Nusantara sejak abad ke 13 M. Namun, yang memeluk Islam saat itu diperkirakan hanya para pedagang dari luar Nusantara. Sementara penduduk asli Nusantara masih memeluk agama-agama lama. Berbagai sumber menyatakan bahwa pemelukan Islam secara masif dari orang-orang Nusantara baru terjadi dua abad berikutnya, yaitu pada era Wali Songo. ${ }^{24}$

Keberhasilan dakwah wali Songo inilah yang menjadi renungan para kiai dan intelektual NU sejak zaman dahulu. Tak sedikit dari mereka yang bertanya-tanya; apa yang istimewa dari dakwah para wali itu sehingga banyak orang melepas agama lamanya dan berpindah ke agama baru-Islam. Setelah mempelajari sejarah, para pengusung Islam Nusantara berkesimpulan bahwa dakwah para wali itu mengikuti pola dakwah Nabi Muhammad; Islam disebarkan dengan penuh rahmat dan kasih sayang. Para wali lebih mendahulukan cara dialog ketimbang konfrontasi. Masyarakat kerap dibiarkan menjalankan tradisi leluhurnya sambil sedikit demi sedikit ajaran tauhid diinjeksikan ke dalamnya. Memberantas kemungkaran pun tak dilakukan dengan cara-cara mungkar (al-nabyu an almunkar bi ghair almunkar). ${ }^{25}$

Mengikuti pola turunnya wahyu yang tak sekaligus, para sufi Nusantara tak memaksa orang-orang yang baru masuk Islam untuk langsung melaksanakan syariat secara penuh. Syariat Islam dijalankan bertahap mengikuti tingkat kesiapan dari masyarakat. Sebagaimana dicontohkan Nabi Muhammad, Islam didakwahkan para wali itu secara bertahap (al-tadrij fi al-tasyri), tak memberatkan ('adam al-baraj), dan tak banyak beban (taqlil al-takalif). Cara-cara ekstrem (tatharruf) dalam penyelesaian masalah dijauhi para wali. Menurut KH Said Aqil Siradj, dalam menyebarkan Islam, para sufi Nusantara berdiri di atas prinsip toleransi (tasamub) dan moderatisme (tawassuth). Dengan prinsip toleransi, Sunan Kudus pernah

\footnotetext{
${ }^{24}$ Romli, dkk, Islam Kita, h. 143.

${ }^{25}$ Romli.
} 
melarang umat Islam menyembelih sapi khusus daerah Kudus Jawa Tengah sebagai bentuk penghormatan terhadap umat Hindu yang memercayai kesucian binatang tersebut. ${ }^{26}$

\section{Gambaran Umum Masyarakat Muslim di Thailand}

Negara Thailand adalah negara monarki kerajaan dengan penganut multi-religi, Menurut Kantor Statistik Nasional Pemerintah Thailand, dari perkiraan 64 juta penduduk Thailand, ada sekitar 94 persen penduduknya beragama Budha dan 5 persen beragama Islam; Namun, perkiraan oleh organisasi non-pemerintah, akademisi, dan kelompok agama menyatakan menyataan bahwa sekitar 85 sampai 90 persen populasi adalah penganut Budha (Theravada) ${ }^{27}$ dan sampai 10 persen dari populasi tersebut beragama Islam. Ada populasi animisme, Kristen, Konghucu, Hindu, Yahudi, Sikh, dan Tao yang kecil. Menurut Departemen Agama (RAD), jumlah atheis atau orang yang tidak menganut agama mencapai kurang dari 1 persen dari populasi. ${ }^{28}$

Dari data di atas menunjukkan bahwa Islam adalah agama terbesar ke-2 setelah Budha, namun tetap saja muslim menjadi kaum minoritas di Thailand. Mayoritas muslim Thailand bertempat tinggal di 3 provinsi paling selatan yaitu Narathiwat, Pattani, dan Yala, sebagian besar juga meyesebar di provinsi-provinsi lain. Kebanyakan Muslim Thailand adalah keturunan Melayu, mencerminkan warisan budaya bersama provinsi Thailand yang paling selatan berbagi dengan Malaysia. Muslim Thailand sendiri terdiri dari sembilan puluh sembilan persen Sunni dan satu persen Muslim Thailand Syi'ah

Berbicara tentang Islam Thailand, maka tidak lepas dengan sejarah Kerajaan Pattani Darussalam, ${ }^{29}$ yang ditaklukkan Siam pada tahun 1785, kemudian diikuti oleh aneksasi tahun 1902. Pattani (Patani) atau Kesultanan Pattani adalah sebuah kesultanan Melayu yang diperkirakan meliputi wilayah provinsi Thai modern Pattani (Patani), Yala (Jala), Narathiwat (Menara), sebagian Songkhla (Singgora), dan bagian paling utara Malaysia modern. ${ }^{30}$ Pada awalnya, Patani merupakan sebuah kerajaan Melayu Islam yang berdaulat, mempunyai kesultanan dan perlembagaan tersendiri. Patani adalah sebagian dari 'Tanah Melayu'. Namun pada pertengahan abad ke-19 Patani telah menjadi korban penaklukan Kerajaan Siam. Pada tahun 1826 penaklukan Siam terhadap Patani mendapat pengakuan Britania Raya. 1902 Kerajaan Siam melaksanakan undang-undang Thesaphiban, sehingga sistem pemerintahan kesultanan Melayu telah dihapuskan. Dengan ditandatanganinya Perjanjian Bangkok pada tahun 1909, Pattani telah diakui oleh Britania sebagai bagian dari jajahan Siam. ${ }^{31}$

Islam berkembang cepat di wilayah selatan yaitu di Provinsi Patani, Yala dan Narathiwat ditambah dengan sebagian Satun, Songkhla dan Krabi. Kawasan Patani, Yala dan Narathiwat merupakan daerah rawan konflik ${ }^{32}$ dengan latar belakang agama dan etnis.

\footnotetext{
${ }^{26}$ Romli, h, 143-144.

27 Theravada merupakan mazhab tertua Agama Buddha yang masih bertahan.

28 U.S. State Department of Thailand, "International Religious Freedom Report 2006: Bureau Of Democracy, Human Rights, And Labor” (https://www.state.gov/j/drl/rls/irf/2006/71359.htm)

29 Baca juga Thanet Aphornsuvan, Thammasat University, "History and Politics of The Muslims in Thailand, Revised 12/2/3. Dan baca juga Raymond Scupin, "Islam in Thailand before The Bangkok Period" JSS 68.11980 untuk memperkaya informasi tentang Patani Darussalam.

30 Periksa juga Wasp Eusocialist Republic "Cara Thailand Lolos dari Penjajahan Bangsa Eropa", untuk pengayaan informasi.

${ }^{31}$ Wikipedia, "Provinsi Patani" 2017

32 Jika disamakan dengan kasus di Indonesia, maka seperti terjadinya pemberontakan di Aceh yang dikobarkan oleh Gerakan Aceh Merdeka (GAM) untuk memperoleh kemerdekaan dari Indonesia antara tahun 1976 hingga tahun 2005.
} 
Terlebih Thailand beberapa kali dipimpin oleh rezim yang sangat mendiskriminasi masyarakat Melayu Muslim seperti Jenderal Phibul Songkhram dan Perdana Menteri Thaksin Shinawatra dimana masyarakat Melayu Muslim menjadi sasaran mangsa asimilasi kebudayaan. Muslim dipaksa untuk menanggalkan identitas Melayu Islam dan mengganti dengan segala bentuk identitas bercorak Thailand dan Budha. Hingga saat ini komunitas Melayu Muslim minoritas khususnya di wilayah selatan masih terus menghadapi diskriminasi yang kompleks serta teror yang masif dan terjadi secara berkala. ${ }^{33}$ Kebijakan asimilasi budaya tersebut menyebabkan trauma panjang mempengaruhi perekonomian, turunnya kesetaraan hak.

Konflik yang berlarut-larut menjadikan sebagian kecil Masyarakat Melayu Muslimpun kemudian berdiri melakukan perlawanan dalam kurun waktu yang panjang dikarenakan kebijakan asimilasi ini. $^{34}$ Meskipun demikian, sekarang kerajaan Thailand cukup mensupport kehidupan Islam untuk penduduknya. Tanggungjawab masalah berkaitan agama Islam di Thailand diemban oleh seseorang mufti yang memperoleh gelar Syaikhul Islam (Chularajmontree). Mufti ini ada di bawah kementerian dalam negeri serta juga kementerian pendidikan serta bertanggungjawab pada raja. Mufti bertugas buat mengatur kebijakan yang bersangkutan dengan kehidupan muslim, seperti penentuan awal serta akhir bulan hijriah, pemerintah juga memberikan bantuan keuangan dan fasilitas primer dan skunder untuk institusi pendidikan Islam, bantuan pembangunan beberapa masjid yang lebih besar, dan dana ziarah oleh Muslim Thailand ke Mekkah, baik Bangkok maupun kota Hat Yai sebagai gerbang utama kota. ${ }^{35}$

\section{Hubungan Genealogis Thailand dan Indonesia}

Ada keselarasan hubungan genealogis dalam keilmuan-keislaman di kepulauan Nusantara. Marzuki Abubakar dalam studinya menjelaskan bahwa kitab Jawi tersebar di berbagai daerah di Nusantara dengan variasi penulis, asal daerah, serta keilmuan yang bermacam-macam. Kitab jawi tersebut sebagiannya masih dikaji dan menjadi sumber referensi dalam kajian Islam di Asia Tenggara seperti di Indonesia, Malaysia dan Thailand. Sebagian besar ulama di Nusantara, apalagi mereka yang hidup dari abad ke-18 dan 19, bahkan sampai sekarang memiliki hutang budi terhadap kitab Jawi. Mereka yang belajar agama, baik di Meunasah dan Dayah (Aceh), Surau (padang), pesantren (Jawa) dan Pondok (Malaysia dan Thailand) semuanya menggunakan kitab jawi ${ }^{36}$ untuk belajar ilmu-ilmu agama Islam. ${ }^{37}$

Ali Matin, ulama Thailand menjelaskan ada hubungan sejarah yang panjang antara Indonesia dan Thailand. Dia menjelaskan bahwa Sunan Gresik pernah belajar kepada Syekh Said Al-Basisa di Patani Thailand. Lebih lanjut dia menceritakan bahwa ada orang Indonesia yang juga ikut berjuang bersama kaum muslim dalam peperangan di antara

33 Teror di sini dimaksudkan sebagai tindakan pemerintah (Askar/tentara) untuk mengeksekusi kaum pejuang (menginginkan Patani merdeka). Adapun eksekusinya berupa tembak mati untuk pejuang yang telah di target pemerintah. Pemerintah memiliki daftar target dan di peringkat, siapa yang akan dieksekusi terlebih dahulu. Foto merekapun dipajang di jala-jalan provinsi Yala, Patani dan Narathiwat.

34 Bayu Mitra Adhyatma Kusuma, "Masyarakat Muslim Thailand dan Dampak Psikologis Kebijakan Asimilasi Budaya” Jurnal Hisbah, Vol. 13, No. 1 Juni 2016

${ }^{35}$ Wikipedia, "Islam in Thailand"

36 Baca juga Arwansyah, Faisal Ahmad Shah, "The Role of the Syaikh Nawawi Al-Bantani in Islamic Dakwa in the Indonesia Archipelago" Kontekstualita, Vol. 30, No. 1, 2015 untuk pengayaan informasi.

${ }^{37}$ Marzuki Abubakar, Kitab Jawi dan Kontribusinya dalam Kajian Islam di Kepulauan Nusantara (Aceh: Conference Proceedings - ARICIS, 2017), h. 441-448. 
Kedah-Patani melawan kerajaan Siam (Thailand) yang terjadi jauh sesudah tahun 1203 H/1789 M. Pejuang tersebut adalah syekh Abdus Samad Al-Jawi Al-Falembani yaitu seorang ulama yang mengarang kitab Hidayatus Solihin. ${ }^{38}$

Raymond Scupin menjelaskan dalam studinya, bahwa sebuah rombongan besar Muslim Indonesia juga pernah menetap di Thailand tengah pada periode Ayudhya. Setelah Belanda menaklukan pelabuhan Makasar oleh komandan angkatan laut Belanda Cornelius Speelman pada tahun 1667 menyebabkan migrasi berbagai pengungsi politik. ${ }^{39}$ Dalam proses observasi, mendapat pengakuan dari Hayatee Salee ${ }^{40}$ bahwa ayahnya adalah orang Indonesia yang dibuang di Thailand oleh tentara Belanda. Lalu sejak awal 2000-an, orang Indonesia banyak berimigrasi ke Thailand untuk berdagang, mengajar, Cultural-social-student exchange hingga ada yang menikah dengan orang Thailand lalu menetap bertahun-tahun di sana. Ada banyak bukti otentik di lapangan menunjukkan bahwa hubungan genealogis antara Indonesia dan Thailand sangat erat, bahkan dari zaman dahulu sampai pada zaman sekarang.

Sesuai data Konsulat Republik Indonesia di Songkhla Thailand per 29 Februari 2015, WNI yang ada di Thailand selatan mencapai 815 orang, data ini diperkirakan jauh lebih banyak tiga kali lipat dari jumlah yang melapor, dikarenakan tidak ada tujuh jalur masuk ke Thailand, lima diantaranya melalui jalur darat Malaysia. Di samping itu belum lagi jumlah WNI yang berlabuh sementara mencapai 1000 orang. ${ }^{41}$ Bagi remaja Thailand Selatan, Indonesia adalah salah satu tujuan favorit untuk melanjutkan studi. Data dari KRI Songkhla menunjukkan bahwa satu dari tiga remaja Thailand Selatan menyatakan ingin menempuh studi/sekolah di Indonesia. Juga pada setiap tahunnya, setidaknya ada 600 pelajar/mahasiswa Thailand Selatan melanjutkan studinya di Indonesia baik dengan biaya sendiri maupun beasiswa. Dari data laporan ini juga menunjukkan ada sekitar 2000 orang Thailand alumni Indonesia yang tergabung dalam wadah Persatuan Alumni Indonesia di Thailand Selatan (PERSAIT) yang terpusat di provinsi Yala. ${ }^{42}$

\section{Islam Nusantara Thailand}

Thailand pada dasarnya merupakan masyarakat dalam rumpun Melayu, khususnya wilayah Thailand Selatan. Jadi, tidak heran jika memiliki kesamaan dengan hal ihwal di Nusantara. Selain menggunakan bahasa Melayu, di wilayah ini juga memiliki kultur keagamaan yang sama pula. Terhitung sejak abad 15, di Haramain (Mekkah dan Madinah), yang menetap di sana dan belajar agama Islam -dan tak sedikit pula yang mengajar. Sebut saja Syekh Abdusshomad Al Palembani (lahir 1704 M) dan Syekh Yusuf Al Makassari (lahir 1626 M). Di Haramain mereka disebut dengan komunitas "Jawi" atau "Negeri di bawah angin". Siapa komunitas "Jawi" ini? Pada awalnya merujuk pada orang Jawa, namun semakin ke belakang, jawi bukan hanya orang-orang yang berasal dari pulau Jawa saja. Akan

\footnotetext{
${ }^{38}$ Muchlishon Rochmat, Fathoni, "Ulama Thailand Ungkap Hubungan Erat Islam di Indonesia dan Thailand” Jakarta, NU Online, 2016

${ }^{39}$ Raymond Scupin, Islam In Thailand Before The Bangkok Period (USA: JSS 68.1, 1980), h. 67.

${ }^{40}$ Hayatee Salee adalah seorang wanita umur 30 tahunan. Wanita yang bekerja sebagai supir Van antar kota (transportasi umum Thailand, di Indonesia mobil elf) ini berkediaman di Distrik Kong Ra, Provinsi Phattalung, Thailand.

${ }^{41}$ Konsulat Republik Indonesia Songkhla, "Rencana Strategis Konsulat Republik Indonesia di Songkhla" Tahun 2015-2019, h. 8-9.

${ }^{42}$ Konsultat. h. 7.
} 
tetapi menunjukkan entitas yang meliputi wilayah Asia Tenggara dewasa ini. ${ }^{43}$ Termasuk Thailand saat ini, di mana, salah satu daerahnya yang cukup dikenal kala itu, adalah Patani.

Dengan adanya manifestasi konsep Islam Nusantara di Indonesia yang berbentuk menjadi ritual keagamaan, dimana ritual ini dihasilkan dari akulturasi budaya lokal dengan agama Islam, lalu Islam menyeleksi sesuai dengan ajaran Islam. Mengacu pada bentuk manifestasi konsep Islam Nusantara yang telah diterapkan di Indonesia penulis ingin menguraikan bagaimana saja bentuk manifestasi konsep Islam Nusantara Thailand Selatan.

Pendidikan, di Thailand muslim Thailand melakukan kegiatan belajar mengajar di sekolah formal (Madrasah) ${ }^{44}$ maupun non-formal (Tadika) ${ }^{45}$ juga Pondok (pesantren). Pondok dipimpin oleh Baba (baca: Babo, yaitu sebutan Kiyai), lalu untuk jumlah nakrian (santrinya) bisa sampai 2000-5000 santri dalam satu pondok untuk di wilayah Narathiwat, Patani dan Yala, sedangkan untuk wilayah yang lain santrinya berjumlah antara 100-1000 santri. Di pesantren Thailand juga mempelajari kitab kuning, seperti: Mushtholah Al-hadits, Arba'in Nawawi, At-Taqrib, Aqidatul Awam, Ta'limul Muta'alim, Nadlom Amtsilati Tashrifiyah untuk belajar shorof, dan Matan Jurumiyah untuk belajar nahu. Ada beberapa pesantren tahfidzul Quran. kitab kuning/jawi mewarnai khasanah keilmuan muslim Thailand Selatan. Pada tahun 1961 pemerintah Thailand mengeluarkan suatu kebijakan pondok tradisional menjadi sistem pondok modern atau sekolah pondok swasta, selanjutnya mendapatkan bantuan finansial untuk pengebangan pesantren. ${ }^{46}$

Bahasa, jika di Indonesia ada istilah bahasa/tulisan pegon, di Thailand pun juga ada, dan lebih dikenal sebagai bahasa jawi, yaitu bahasa Melayu yang dituliskan menggunakan huruf Arab (bijaiyyab). Sedangkan makna gandul ditulis menggunakan huruf Thai untuk mengartikan kitab kuning, atau kitab-kitab berbahasa jawi lainnya.

Amalan, dilihat dari amalan-amalannya muslim Thailand selatan sering sekali melaksanakan tablilan, ${ }^{47}$ yasinan, istighosah, barjanzi (berjanjen), sholawatan atau lebih dikenal sebagai nasyid. Di phattalung sendiri yang notabenenya muslim masih sedikit, acara yasinan minimal dilakukan sekali dalam seminggu yaitu pada malam hari Kamis, atau hari Jumat. Yasinan juga biasa dilaksanakan ketika ada syukuran, ta'riyah mayit, ziarah dll.

Budaya / Adat, muslim Thailand selatan sangat sering melakukan selametan, kenduri (genduri / kenduren), kenduri biasanya dilakukan ketika ada hajatan, membangun rumah, mendapatkan rezeki, seperti lumrahnya kenduri di Indonesia. Ketika dilaksanakan selamatan atau kegiatan kemasyarakatan lain, biasanya warga sekitar atau keluarga melakukan jagongan sehari full, bahkan sampai tiga hari. Berkatan, biasanya hanya diberikan ketika salat jenazah di masjid, selain itu biasa dilakukan juga doa untuk mayit dam 3 hari berturut-turut, tapi

${ }^{43}$ Muhammad Pizaro dkk, Islam Nusantara: Islamisasi Nusantara atau Menusantarakan Islam? Terbit 1 Agustus 2015

${ }^{44}$ Sekolah ini memiliki kurikulum gabungan antara mata pelajaran Islam yang disusun oleh tim sekolah dan mata pelajaran umum yang disusun oleh kerajaan. Pelaksanaan KBM dari senin sampai jumat, full day school dari jam 7.00-16.00.

${ }^{45}$ Tadika merupakan sekolah malam atau hari Sabtu dan ahad. Tadika hanya mengajarkan tentang mata pelajaran agama Islam. Kebanyakan kegiatan belajar mengajar dilaksanakan di Masjid atau di gedung sekolah formal. Tadika seperti ini banyak berada di provinsi Narathiwat, Yala dan Patani.

${ }^{46}$ Perikasa, Sifa Fauziah, "Sejarah Perkembangan Pendidikan Islam di Thailand Selatan (Patani) pada Abad ke-XVII sampai XX M (Jakarta: UIN Syarif Hidayatullah, 2011) untuk pengayaan kajian

47 Periksa Fahmi Nuris Syafa'at, "Menengok Islam di Thailand" NU Online Banyuwangi 2017, untuk menambah informasi. 
hanya untuk orang-orang yang diundang, lalu sebagian ada yang melakukan doa 7 hari, 40, 100 dan 1000 hari setelah kematian. ${ }^{48}$

Seni, jika di Indonesia ada pagelaran wayang kulit, maka di Thailand juga ada yang disebut Nang Talung. ${ }^{49}$ Nang Talung adalah permainan bayangan tradisional, yang merupakan hiburan favorit bagi masyarakat di Thailand selatan yang telah menjadi simbol kehidupan lokal di wilayah tersebut. Pertunjukan dan artistiknya biasanya disertai dengan kombinasi lagu dan nyanyian moral, beberapa di antaranya telah disesuaikan sesuai perubahan ekonomi, politik, sosial dan budaya. Diyakini bahwa seni Nang Talung ini berasal dari Wayang Kulit Jawa. ${ }^{50}$ Selajutnya ada seni Sholawat yang biasa disebut Nasyid oleh orang Thailand, dimana menurut orang Thailand seluruh lagu religi atau yang berbahasa Melayu adalah nasyid. Sholawat khas Indonesia sudah banyak tersebar di Thailand Selatan, seperti sholawat nariayah, Ya Asyiqol Musthofa, bahkan lagu religi Wali Band serta lantunan sholawat Habib Syech sudah banyak dihafal oleh orang Thailand. Hal ini disebabkan ketika ada Warga Negara Indonesia (WNI) yang tinggal di Thailand membawa atau melantunkan sholawat-sholawat tersebut, lalu tersebarlah.

Perayaan Maulid Nabi Muhammad di rayakan oleh orang Thailand dengan mengadakan tausiyah keagamaan oleh pemuka agama, seperti di Indonesia tidak semua merayakan, hanya orang-orang tertentu dan biasanya madrasah atau pondok pesantren yang mengadakannya. Pada hari ke-17 Ramadhan madrasah, masjid, atau pondok pesantren memperingati Nuzulul Quran dengan cara khataman al Quran, dimana setiap santri/peserta dijatah membaca satu juz atau lebih. Lalu pada malam 10 hari terakhir Ramadhan merayakan pencarian malam lailatul qodar dengan cara i'tikaf di masjid penuh. Ada juga yang i'tikaf semampunya. Ketika sekolah libur lebaran/idul fitri, sebelum santri pulang kampung biasanya sekolah melakukan musofahah oleh seluruh guru dan santri/murid, lalu ketika kembali ke pondok dilakukan halal bi halal.

Ibadah, Salat Jumat di Thailand berasa seperti salat di Indonesia terkait pelaksaan dimana ada masjid yang menggunakan dua kali khutbah serta diselingi sholawat dipertangahan, ada juga yang khutbah satu kali. Salat mayit hukumnya fardlu kifayah, artinya jika sudah dilakukan sebagian masyarakat maka gugur sudah kewajiban individu/kelompok lain, namun di Thailand, ketika ada yang meninggal dari satu desa ikut melawat, juga menshalati, bahkan santri/murid putra beserta guru putra rombongan mensalai mayit, dan meninggalkan urusan Kegiatan Belajar Mengajar (KBM). Setelah salat jenazah selesai biasanya jamaah diberi amplop dan berkat untuk dibawa pulang. ${ }^{51}$ Ketika buka puasa Ramadhan di Thailand sering ada buka bersama di rumah-rumah warga sedangkan salat tarawihnya seperti di Indonesia ada yang 20 dan ada yang 10 rakaat, dimana setiap setelah selesai salam diselingi sholawat. Pada tanggal 15 akhir bulan Ramadhan dalam salat sunnah salat witir menggunakan qunut. Lalu ketika Idul Fitri masyarakat Thailand menyempatkan pulang kampung, untuk bersilaturahmi dengan keluarga dan sanak famili. Sedangkan ketika

\section{${ }^{48}$ fahmi}

49 Periksa juga Bing Bedjo Tanudjaja, "Pertunjukan Wayang Kulit Nang Talung, Representasi Kehidupan Masyarakat Thailand Selatan” NIRMANA, Vol. 14, No. 1, Januari 2012,

${ }^{50}$ Nualmorakot Taweethong, "The History of Nang Talung :'Shadow play' from Asia to Southern Thailand" The 2nd International Conference on Humanities and Social Sciences April 10, 2010 Faculty of Liberal Arts, Prince of Songkla University

${ }^{51}$ Periksa Fahmi Nuris Syafa'at, "Guyubnya Sholat Jenazah di Thailand” NU Online Banyuwangi 2017, untuk menambah informasi. 
setelah Idul Adha, beberapa warga berqurban sapi, lalu dibagikan ke masyarakat, sedang selama ayyamuttasriq warga mengundang tetangga dan sanak famili untuk silaturahmi, biasanya bisa keliling ke rumah warga hampir 3-5 kali dalam sehari.

\section{Kesimpulan}

Konsep Islam Nusantara lahir dari kisah keberhasilan dakwah Wali Songo dengan mengikuti pola Nabi Muhamad: Islam disebarkan dengan penuh rahmat dan kasih sayang, juga tidak langsung memaksa melakukan syariat Islam secara penuh, melainkan dijalankan mengikuti kesiapan dari masyarakat. Banyak orang masih memahami bahwa Islam Nusantara adalah Islam di Indonesia, namun pada kenyataannya bentuk manifestasi konsep Islam Nusantara ada di Thailand dengan dimana Indonesia dan Thailand memiliki hubungan genealogis, sejarah, dan pertukaran budaya. Penulis membagi bentuk manifestasi konsep Islam Nusantara ini dalam kategori bahasa, amalan, budaya/adat, seni, perayaan, dan ibadah.

Meskipun tulisan ini bersumber pada data dan waktu yang terbatas, namun setidaknya dapat ditemukan bahwa konsep Islam Nusantara dapat diaplikasikan di Thailand bukan hanya di Indonesia. Disamping itu bagaimanapun juga kajian ini masih dalam lingkup Asia Tenggara, sehingga baik kiranya jika konsep Islam Nusantara ini dikaji lebih luas hingga ke luar benua Asia.

\section{Daftar Pustaka}

Abubakar, Marzuki. Kitab Jawi dan Kontribusinya dalam Kajian Islam di Kepulauan Nusantara. Aceh: Conference Proceedings - ARICIS, 2017.

Aphornsuvan, Thanet. History and Politics of The Muslims in Thailand, Revised. Thammasat University, 2012.

Arwansyah. Shah, Faisal Ahmad. 2015. The Role of the Syaikh Nawawi Al-Bantani in Islamic Dakwa in the Indonesia Archipelago. Kontekstualita, Vol. 30, No. 1.

Astuti, Santi Indra. Cultural Studies dalam Studi Komunikasi: Suatu Pengantar, 2003.

Fauziah, Sifa. Sejarah Perkembangan Pendidikan Islam di Thailand Selatan (Patani) pada Abad keXVII sampai XX M. Jakarta: UIN Syarif Hidayatullah, 2011.

Kauningan, Atur. Tata Cara Bancakan Weton, 2012.

Kusuma, Bayu Mitra Adhyatma. 20166. Masyarakat Muslim Thailand dan Dampak Psikologis Kebijakan Asimilasi Budaya. Jurnal Hisbah, Vol. 13, No. 1.

Listia, Queen Fannis. Islam Nusantara; Upaya Pribumisasi Islam Menurut NU. Surabaya: Digilib Uinsby, 2016.

Luthfi, Khabibi Muhammd. Islam Nusantara: Relasi Islam dan Budaya Lokal. Surakarta: Shahih, 2016.

Moleong, Lexy J. Metodologi Penelitian Kualitatif Edisi Revisi. Bandung: PT. Remaja Rosdakarya Offset, 2006.

Pakar, Sutejo Ibnu. Tuntutan Amaliah Ramadhan Warga Nabdhiyyin Cirebon: Kamu NU, 2015. 
Pizaro Muhammad. dkk. Islam Nusantara: Islamisasi Nusantara atau Menusantarakan Islam?. Terbit 1, 2015.

Republic, Wasp Eusocialist. Cara Thailand Lolos dari Penjajahan Bangsa Eropa.

Rochmat, Muchlishon. Fathoni. Ulama Thailand Ungkap Hubungan Erat Islam di Indonesia dan Thailand. Jakarta: NU Online, 2016.

Romli, Mohamad Guntur, dkk, Islam Kita Islam Nusantara: Lima Nilai Dasar Islam Nusantara. Ciputat: Ciputat School, 2016.

Scupin, Raymond. Islam in Thailand before The Bangkok Period. JSS 68.1, 1980.

Songkhla, Konsulat Republik Indonesia. Rencana Strategis Konsulat Republik Indonesia di Songkbla Tabun 2015-2019. Sonkhla Thailand., 2016.

Syafa'at, Fahmi Nuris. Menengok Islam di Thailand. Banyuwangi: NU Online Banyuwangi, 2017.

Guyubnya Sholat Jenazah di Thailand. Banyuwangi: NU Online Banyuwangi, 2017.

Syafrizal, Achmad. Sejarah Islam Nusantara. Islamuna. Volume 2 Nomor 2, 2015.

Tanudjaja, Bing Bedjo. Pertunjukan Wayang Kulit Nang Talung, Representasi Kehidupan Masyarakat Thailand Selatan. NIRMANA: Vol. 14, No. 1, 2012.

Taweethong, Nualmorakot. The History of Nang Talung :'Shadow play' from Asia to Southern Thailand. Songkhla: The 2nd International Conference on Humanities and Social Sciences. Faculty of Liberal Arts, Prince of Songkla University, 2010.

Thailand, U.S. State Department of. International Religious Freedom Report 2006: Bureau Of Democracy, Human Rights, And Labor (https://www.state.gov/j/drl/rls/irf/2006/71359.htm), 2006.

Wahyudi, Deny Yudo. Kerajaan Majapabit: Dinamika Dalam Sejarah Nusantara Sejarah dan Budaya. Tahun Ketujuh, Nomor 1, 2013.

Wawancara dengan Kholilurrahman Chuldori Ketua PAC Tuban.

Wawancara dengan Mahasiswa KKN-PPL Internasional oleh Badan Alumni Thailand Selatan angkatan ke-8 2017.

Wawancara Hayatee Salee seorang wanita umur 30 tahunan. Wanita yang bekerja sebagai supir Van antar kota (transportasi umum Thailand, di Indonesia mobil elf) ini berkediaman di Distrik Kong Ra, Provinsi Phattalung, Thailand.

Wikipedia. Islam in Thailand.

Wikipedia. Provinsi Patani, 2017. 